\title{
Bioenergetic cost of cryptobiosis in fish: rainbow trout Oncorhynchus mykiss infected with Cryptobia salmositica and with an attenuated live vaccine
}

\author{
F. W. H. Beamish*, A. Sitja-Bobadilla, J. A. Jebbink, P. T. K. Woo \\ Department of Zoology, University of Guelph, Guelph, Ontario, Canada N1G 2W1
}

\begin{abstract}
Food consumption, dry weight and energy gain, energy concentration and gross conversion efficiency were measured in 4 groups of juvenile rainbow trout Oncorhynchus mykiss over a 14 wk study period. The infected group, each fish inoculated with 2000 pathogenic Cryptobia salmositica, showed significant reduction of all of these factors and were anemic during acute cryptobiosis when compared to the control group. A third group fed an amount of food equivalent to that fed to the infected group (pair-fed) displayed energetic relationships similar to those of the control group except for gross conversion efficiency, which was slightly higher. Each fish in the last group was inoculated with 20000 attenuated live C. salmositica and the group was not significantly different from the control group throughout the $14 \mathrm{wk}$ period. These vaccinated fish had very low parasitemia and were resistant to the disease when challenged with the pathogen. Fish that recover from cryptobiosis are immune but at considerable bioenergetic cost whereas vaccination serves as an effective control with little bioenergetic cost to the host.
\end{abstract}

KEY WORDS: Cryptobia salmositica - Oncorhynchus mykiss B Boenergetics . Disease Rainbow trout

\section{INTRODUCTION}

Understanding fish growth and the conditions that influence it is important to the management and rearing of fish under controlled conditions. The bioenergetics approach measures growth with respect to changes in biomass, proximate composition and energy content (Beamish et al. 1975). A bioenergetic model must rationalize the allocation of food consumed into recovered energy or growth, metabolic energy including standard metabolism, voluntary metabolism, heat increment and waste energy (Ricker 1971, Kitchell et al. 1977, Beamish \& Trippel 1990, NRC 1993). A comprehensive bioenergetic model must also endeavour to integrate food processing transactions with factors in the ecosystem that influence energy expenditure (Beamish \& Trippel 1990).

A stressful environment will significantly affect the utilization of energy by influencing the metabolic state

•E-mail: bbeamish@uoguelph.ca of the fish. Conditions existing in hatcheries such as high density, handling, and high and low levels of ammonia and oxygen respectively impose additional energy demands. Crowded conditions result in decreased food conversion efficiency (Brett 1979). Growth is markedly reduced when fish are exposed to low oxygen concentrations for even short periods of time (Brett 1979). The result of such conditions is decreased resistance of the fish to disease and the creation of a favourable environment for a variety of pathogens.

Cryptobia salmositica is a pathogenic hemoflagellate of salmonids on the Pacific coast of North America. It is normally transmitted indirectly through the bite of infected aquatic leeches Piscicola salmositica; however, direct transmission may also occur during the acute phase of the disease when large numbers of parasites appear on the body surface of infected fishes (Woo \& Wehnert 1983). Under certain conditions, direct transmission may be an important mode of infection in hatcheries. The clinical signs of the disease in 
susceptible salmonids include lethargy, anemia, anorexia, exophthalmia, general edema, abdominal distension with ascites, splenomegaly and hepatomegaly. Other features of the disease are decreased glucose and plasma protein levels with reduced glycogen in the heart, epaxial muscle and liver. The severity of the disease and mortality rate vary among fish species and among fish stocks (Woo 1987, 1994)

Adult rainbow trout Oncorhynchus mykiss that recover from the disease are protected when challenged with the pathogen. Humoral and cell-mediated immunity are stimulated during the infection and they are important in recovered fish (Wehnert \& Woo 1981 , Jones \& Woo 1987, Thomas \& Woo 1990). Also, juvenile and adult trout that are vaccinated with an attenuated live stain of Cryptobia salmositica are protected from homologous challenges (Woo \& Li 1990, SitjaBobadilla \& Woo 1994, Li \& Woo 1995). The protection lasts at least 24 mo after vaccination; as in recovered fish, complement fixing antibody and cell-mediated immunity are part of the protective mechanism in vaccinated trout (Li \& Woo 1995).

Knowledge is limited on the bioenergetic cost to an organism in combating a parasite or disease. The purpose of this study was to determine the energy loss in terms of weight gain, energy gain and conversion efficiency to rainbow trout infected with Cryptobia salmositica. In addition, we wanted to determine any energetic cost to rainbow trout vaccinated with an attenuated strain of live $C$. salmositica.

\section{MATERIALS AND METHODS}

Juvenile rainbow trout ( 3 to $5 \mathrm{~g}$ ) were obtained from Goosen's trout hatchery in southern Ontario, Canada, and distributed among twelve $300 \mathrm{l}$ fibreglass tanks. Water exchange was a 100\% flow through system using non-chlorinated groundwater at $936 \mathrm{l} \mathrm{min}^{-1}$ The chemical composition of the water is given in Table 1 Ambient dissolved oxygen and ammonia nitrogen were measured before and after feeding each day during the first $2 \mathrm{wk}$ and thereafter twice weekly. At all times ambient oxygen and ammonia nitrogen were above $8.0 \mathrm{mg} \mathrm{l}^{-1}$ and below $0.1 \mathrm{mg} \mathrm{l}^{-1}$ respectively. Photoperiod was maintained at $16 \mathrm{~h}$ light: $8 \mathrm{~h}$ darkness. Intensity of overhead incandescent lights was gradually increased and decreased for $0.5 \mathrm{~h}$ at either end of the photoperiod. Maximum light intensity at the surface of the uncovered portion of each tank was approximately 60 lux. Water temperature was maintained at $18.0^{\circ} \mathrm{C}$.

Fish were fed to satiation for 10 min once daily with a diet formulated for rainbow trout (GRT-72, Martin Feed Mills, Elmira, Ontario). Energy content of the diet
Table 1. Chemical composition of groundwater ( $R$. Moccia, Department of Animal and Poultry Science, University of Guelph, Guelph, Ontario, Canada, pers. comm.)

\begin{tabular}{|lc|}
\hline Chemical characteristics & Concentration $\left(\mathrm{mg} \mathrm{l}^{-1}\right)$ \\
\hline Alkalinity $\left(\mathrm{CaCO}_{3}\right)$ & 250 \\
Ammonia & $<0.10$ \\
Bicarbonate $\left[\mathrm{Ca}\left(\mathrm{HCO}_{3}\right)_{2}\right]$ & 248 \\
Calcium & 105 \\
Carbon (total organic) & $<1.0$ \\
Chloride & 52 \\
Conductivity $\left(25^{\circ} \mathrm{C}\right)$ & $448 \mathrm{mho} \mathrm{cm}^{-1}$ \\
Hardness $(\mathrm{CaCO})$ & 411 \\
Iron (total) & $<0.02$ \\
Magnesium & 36.2 \\
Nitrate $(\mathrm{N})$ & $<0.05$ \\
pH & $8.0 \mathrm{pH}$ units \\
Phosphorus $($ total) & 0.02 \\
Potassium & 2.2 \\
Sodium & 24.1 \\
Sulphate & 131 \\
\hline
\end{tabular}

was $21.301 \mathrm{~kJ} \mathrm{~g}^{-1}$. This feeding regime was continued until daily consumption did not vary by more than $10 \%$ of the mean over $7 \mathrm{~d}$. A sample of 10 fish were then killed by a sharp blow to the head and freeze-dried to constant weight for determination of body water content.

The virulent Cryptobia salmositica was obtained from blood of an experimentally infected fish. The parasite was initially isolated from its natural vector, the leech Piscicola salmositica (Woo 1978), and was maintained in the laboratory by passage through rainbow trout and cryopreservation in liquid nitrogen (Woo 1979). The C. salmositica vaccine used was a live strain attenuated by continuous in vitro culture (Woo \& Li 1990) and maintained in Minimum Essential Medium at $10^{\circ} \mathrm{C}$.

Phosphate buffered saline (PBS, $\mathrm{pH} 7.4$ ) was used to dilute both the infected blood and the vaccine strain. The number of parasites was estimated using a hemocytometer (Archer 1965). The absence of parasites was confirmed by the hematocrit centrifuge technique (Woo 1971)

On July 12, 1993, all fish were weighed and 35 fish were added to each of the 12 tanks. Average weight $( \pm \mathrm{SD}$ ) of each fish was $12.6 \pm 4.4 \mathrm{~g}$. The 12 tanks corresponded to 4 treatment groups each with 3 replicates. In Group I, the infected group, each fish was injected intraperitoneally (ip) with 2000 pathogenic Cryptobia salmositica in $0.1 \mathrm{ml}$ of PBS. Fish in Group III, the vaccinated group, were each immunized ip with 20000 attenuated live $C$. salmositica vaccine in $0.1 \mathrm{~mL}$ PBS. Fish in Groups II and IV, pair-fed and control groups respectively, were each injected ip with $0.1 \mathrm{ml}$ PBS only. 
Each day fish in Groups I, III and IV were fed all the food they could consume in $10 \mathrm{~min}$. Fish in Group II (pair-fed) were fed the same amount of food relative to their total body weight as a corresponding replicate of Group I. The purpose of pair feeding was to determine the energy cost of infection-induced reduction in food consumption. The amount of food consumed by each group was recorded daily.

Two fish from each tank ( $\mathrm{n}=24$ ) were killed prior to infection, by an overdose of methane tricaine sulfonate $10.01 \%$ w/v; Argent Chemical Laboratories, Redmond, Washington, USA) to obtain initial energy content. Fish were individually weighed and measured and 15 fish from each group $(n=60)$ were sampled for energy analysis at 4, 6, 8, 12 and $14 \mathrm{wk}$ post-infection. Fish were weighed by tank at 2 and $10 \mathrm{wk}$ post-infection to determine weight gain.

Each sampled fish was weighed then freeze-dried to constant weight for determination of body water content. Afterwards, fish were homogenized and stored in desiccators. Energy content was determined for whole fish using an adiabatic bomb calorimeter. Corrections were made for burnt fuse wire and nitric acid (Parr lnstrument Company 1960). All energy analyses were performed at least in duplicate.

Gross energy conversion efficiency was calculated according to Brett \& Groves (1979). Gross energy conversion efficiency was determined for each interval in which fish were sampled.

Differences in food consumption, weight and energy gain, energy concentration and gross conversion efficiency were analyzed using analysis of variance (ANOVA). Tukey's studentized range test was used for comparison of means. Significance level was $5 \%(p<0.05)$ for all tests.

Blood was obtained by caudal severance, collected in heparinized hematocrit tubes and used to determine the packed cell volume (PCV), parasitemias, and the antibody titre against the parasite in air-dried filter paper samples as reported earlier (Sitja-Bobadilla \& Woo 1994). Also, blood from 5 fish was obtained $1 \mathrm{~d}$ before the injection ( $0 \mathrm{wk}$ ).

Two days after the last sampling, 3 fish from each replicate of Groups III ( 9 vaccinated fish) and IV (9 control fish) were injected ip with the virulent parasite $(2000$ parasites fish $^{-1}$ ), whereas 3 fish from each replicate of Group III remained unchallenged. These new sub-groups were kept in separate tanks. Four weeks after the challenge, parasitemias in the fish were determined as before.

The antibody titre against Cryptobia salmositica was determined by an enzyme- linked immunosorbent assay (ELISA) as previously described (Sitja-Bobadilla \& Woo 1994), using a phosphatase-labelled goat anti-rainbow-trout immunoglobulin at a dilution of 1:250. Each sample was tested in duplicate and appropriate controls were included in all assays. The results are expressed in optical density (OD) readings at $405 \mathrm{~nm}$, in which the background non-specific binding was assayed of wells to which all reagents except the sample had been added.

A Kruskal-Wallis 1-way ANOVA was applied to determine statistical differences amongst groups and within a group at different sampling points, with regard to parasitemia, PCV and antibody titre. Multiple comparisons among means were made with Dunn's method when the ANOVA value was significant $(\mathrm{p}<$ 0.01) (Steel \& Torrie 1980).

\section{RESULTS}

A total of 6 mortalities occurred between Weeks 3 and 8 post-infection among the 3 tanks of Group I (infected) fish. Other mortalities included 1 in each of 2 tanks of Group IV (control) fish in Weeks 3 and 8 postinfection, and 1 in each of 2 tanks of Group III (vaccinated) fish in the final week of the study. Parasitemias and mortalities were very low in Group III 10 and 825000 Cryptobia ml $^{-1}$ ) (Fig 1).

At 4 wh post-infection parasitemia peaked in Group I (infected) fish, whereas it was low in Group III (vaccinated) fish. Although parasitemia decreased gradually

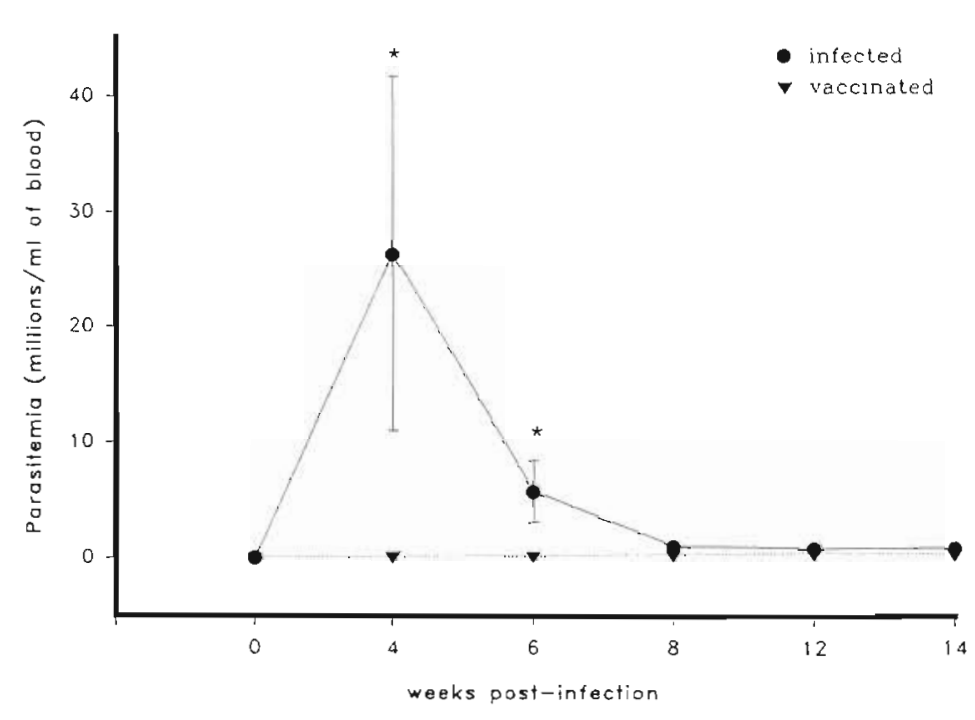

Fig. 1. Oncorhynchus mykiss. Parasitemias in rainbow trout either infected with Cryptobia salmositica or vaccinated with attenuated live $C$. salmositica (means $\pm \mathrm{SD}$ of 15 fish). "Significantly higher parasitemias $(p<0.01)$ 


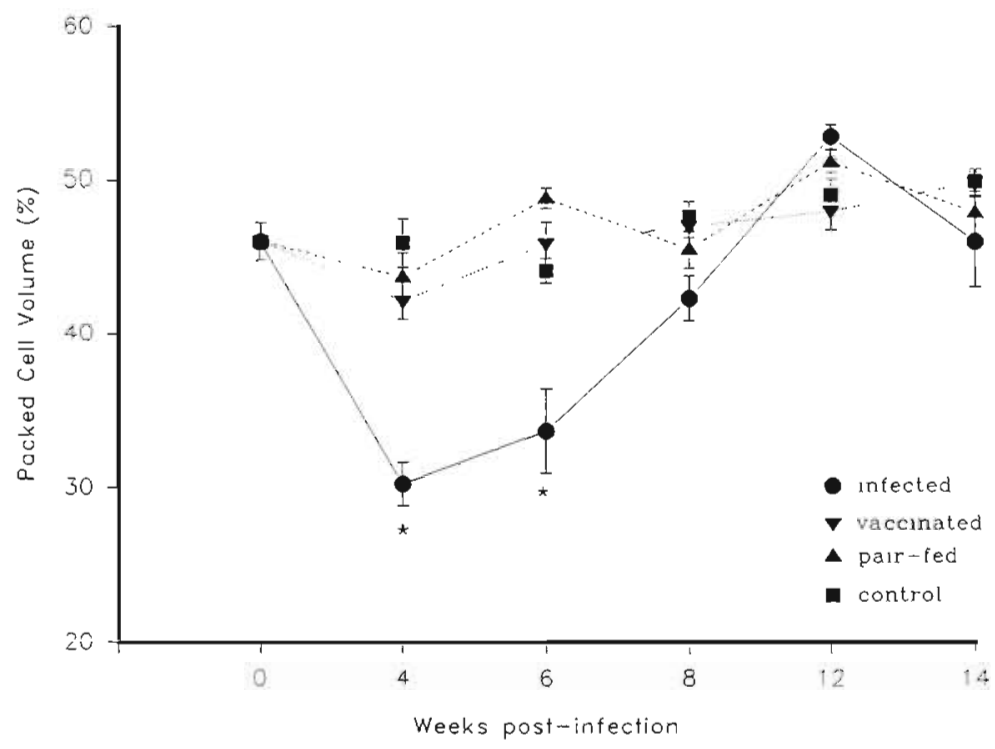

Fig. 2. Oncorhynchus mykiss. Packed cell volume of 4 treatment groups in relation to post-infection time (means \pm SD of 15 fish). *Significantly lower $\operatorname{PCV}(p<0.01)$

in Group I and increased slightly in Group III through the subsequent samplings, vaccinated fish had significantly $(p<0.01)$ lower parasitemia than infected fish at 4 and 6 wk post-infection (Fig. 1). There were no parasites in the blood of fish from Groups II (pair-fed) and IV (control) at any sampling time.

PCV of Group I (infected) fish was significantly lower than that of Group IV (control) fish at 4 wk post-infection, in coincidence with the peak of parasitemia, and significantly lower than that of Group II (pair-fed) fish at 6 wk post-infection (Fig. 2). Although the PCV remained lower than those of the rest of the groups at 8 wk post-infection, the differences were not statistically significant. The slight decrease in PCV detected in Group II fish at 4 wk post-infection was not significant. AIso, the slight variations detected in Groups III and IV during the experiment were not significant (Fig. 2).

The antibody titre of Group III (vaccinated) fish did not differ significantly from that of Group IV (control) and Group II (pair-fed) fish through the experimental period, and thus data are not shown. The mean antibody titre detected in Group I (infected) fish during the experimental period is compared with those in Group II and IV fish (Fig. 3). At 4 wk post-infection, Group I fish showed decreased ELISA OD compared to both Group II and Group IV fish, coincident with the peak of parasitemia. This negative difference was higher at 6 wk post-infection when compared with the pair-fed fish. Subsequently, Group I fish showed increased antibody titre though positive differences were statistically significant only between Groups I and IV at 8 and 12 wk post-infection
Food consumption by fish in all groups remained relatively constant throughout the $14 \mathrm{wk}$ study. Through the first 4 wk post-infection, food consumption $\left(\mathrm{mg} \mathrm{g}^{-1}\right.$ fish $\mathrm{d}^{-1}$ ) did not differ significantly among replicates or among groups $\left(F_{\{3,8\}}=4.07\right.$, $p>0.05$ ). Tukey's studentized range test for comparison of means (critical value $=4.53$ ) indicated that food intake for Groups I and II (infected and pair fed respectively) was significantly lower than in Groups III and IV (vaccinated and control respectively) for the interval 4 to $6 \mathrm{wk}$ post-infection when the parasitemias were high (Fig. 1). Through the interval 6 to 8 wk post-infection, food intake for Group IV was significantly higher than for Groups II and III, but not higher than for Group I. Food intake decreased slightly and was similar in all groups through the last 4 wk of the study. Relative food consumption for all groups ranged between 1.6 and $1.8 \%$ of live body weight daily for the first half of the study with the exception of Group IV which increased to $2.1 \%$ through the interval 4 to 8 wk post-infection. Relative food consumption of all groups declined to $1.5 \%$ through Weeks 10 to 14 post-infection.

Initial mean weight of fish varied from 11.0 to $14.1 \mathrm{~g}$ among the tanks. Live body weight did not vary significantly among treatments at any sampling time over the 14 wk study. However, live weight gain in Group I

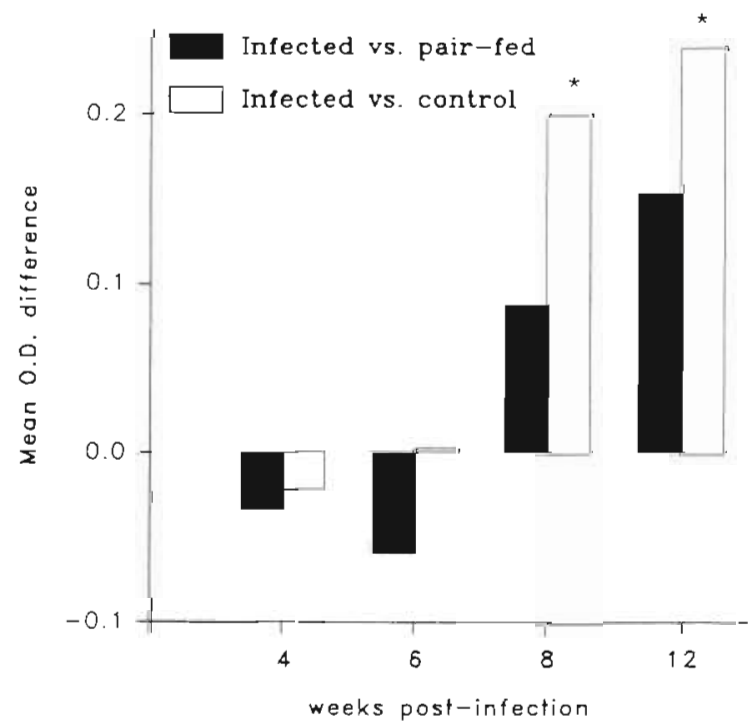

Fig. 3. Oncorhynchus mykiss. Comparison of mean antibody titre (optical density) of infected fish with those of pair-fed and control fish in relation to post-infection time. * Significantly higher optical density $(p<0.01)$ 
(infected) fish was significantly lower than in all other groups at 6 and 8 wk post-infection. Body water content in all groups at the start of the experiment was $72.93 \pm 1.20 \%$ and remained at a similar concentration throughout the $14 \mathrm{wk}$, with the exception of Group I. Water content in these fish peaked 6 wk post-infection $(75.12 \pm 2.50 \%)$ and was significantly higher than in all other groups. For the remainder of the study, water content of Group I fish decreased steadily and was similar to that for the other groups by the end of the study. Because of this edema, dry weight gain was considered to be a more accurate indicator of growth. Analysis of each sampling period indicated that dry weight gain was significantly different among the groups for 6 and $8 \mathrm{wk}$ post-infection $\left(F_{(3,8)}=4.07, \mathrm{p}<0.05\right)$. Tukey's studentized range test (critical value $=4.53$ ) showed that weight gain in Group I (infected) was significantly lower than all other groups and that weight gain in
Group IV (control) was significantly higher than that in all other groups $6 \mathrm{wk}$ post-infection (Table 2). At $8 \mathrm{wk}$ post-infection, dry weight gain in Group I was significantly lower only than that in Group IV (Table 2). Weight gain in Groups II (pair-fed) and III (vaccinated) was similar throughout the 14 wk study. All 4 groups, however, showed a noticeable increase in weight gain in Weeks 10 and 12 post-infection.

Energy concentration peaked in all groups $8 \mathrm{wk}$ post-infection although the increase was slight in Group I (infected) fish (Table 3). At this time energy concentration in Group I fish was significantly lower than in Group IV (control). By the end of the $14 \mathrm{wk}$ study, energy concentration had levelled off in all 4 treatment groups and no significant differences were found $\left(F_{(11,48)}=1.99, \mathrm{p}>0.05\right)$.

Energy gain per fish increased steadily in all treatment groups throughout the study (Table 4). Highest

Table 2. Oncorhynchus mykiss. Dry weight gain (g fish ${ }^{-1}$, mean $\pm \mathrm{SD}$ of $15 \mathrm{fish}$ )

\begin{tabular}{|c|c|c|c|c|c|c|c|}
\hline \multirow[t]{2}{*}{ Treatment } & \multicolumn{7}{|c|}{ Weeks post-infection: } \\
\hline & 2 & 4 & 6 & 8 & 10 & 12 & 14 \\
\hline Infected & $0.95 \pm 0.12$ & $1.74 \pm 0.22$ & $1.59 \pm 0.24^{\mathrm{d}}$ & $2.20 \pm 0.34^{\mathrm{b}}$ & $3.43 \pm 1.08$ & $2.73 \pm 0.67$ & $3.77 \pm 0.66$ \\
\hline Pair-fed & $1.13 \pm 0.15$ & $1.69 \pm 0.18$ & $2.15 \pm 0.18$ & $2.85 \pm 0.19$ & $3.47 \pm 0.62$ & $2.94 \pm 0.33$ & $4.17 \pm 0.64$ \\
\hline Vaccinated & $1.05 \pm 0.06$ & $1.40 \pm 0.12$ & $2.22 \pm 0.08$ & $2.77 \pm 0.13$ & $3.72 \pm 0.43$ & $3.40 \pm 0.16$ & $3.58 \pm 1.85$ \\
\hline Control & $1.05 \pm 0.23$ & $1.63 \pm 0.22$ & $2.74 \pm 0.13$ & $3.29 \pm 0.31$ & $4.40 \pm 0.50$ & $3.61 \pm 0.41$ & $4.85 \pm 0.57$ \\
\hline
\end{tabular}

Table 3. Oncorhynchus mykiss. Energy concentration ( $\mathrm{kJ} \mathrm{g}^{-1}$, mean $\pm \mathrm{SD}$ of 15 fish)

\begin{tabular}{|c|c|c|c|c|c|}
\hline Treatment & 4 & 6 & $\begin{array}{l}\text { eeks post-infection: } \\
8\end{array}$ & 12 & 14 \\
\hline Infected & $24.743 \pm 0.012$ & $23.422 \pm 0.612$ & $25.692 \pm 0.103^{\circ}$ & $25.813 \pm 0.341$ & $24.434 \pm 0.291$ \\
\hline Pair-fed & $24.644 \pm 0.992$ & $24.841 \pm 0.622$ & $26.149 \pm 0.348$ & $25.324 \pm 0.523$ & $25.592 \pm 0.256$ \\
\hline Vaccinated & $25.036 \pm 1.286$ & $25.356 \pm 0.346$ & $25.971 \pm 0.250$ & $24.709 \pm 0.318$ & $25.632 \pm 0.305$ \\
\hline Control & $25.085 \pm 1.009$ & $24.803 \pm 0.306$ & $26.413 \pm 0.088$ & $25.306 \pm 0.319$ & $25.527 \pm 0.474$ \\
\hline
\end{tabular}

Table 4. Oncorhynchus mykiss. Energy gain ( $\mathrm{kJ} \mathrm{g}^{-1}$, mean $\pm \mathrm{SD}$ of 15 fish)

\begin{tabular}{|c|c|c|c|c|c|}
\hline Treatment & 4 & 6 & $\begin{array}{c}\text { eks post-infect } \\
8\end{array}$ & 12 & 14 \\
\hline Infected & $42.96 \pm 5.48$ & $40.35 \pm 6.10^{\mathrm{a}}$ & $56.58 \pm 8.67$ & $70.28 \pm 17.05$ & $95.87 \pm 16.47$ \\
\hline Pair-fed & $41.59 \pm 2.67$ & $53.35 \pm 5.68$ & $74.62 \pm 5.00$ & $74.40 \pm 8.52$ & $106.79 \pm 15.56$ \\
\hline Vaccinated & $35.09 \pm 3.95$ & $56.47 \pm 2.42$ & $71.85 \pm 3.52$ & $84.04 \pm 4.02$ & $92.09 \pm 48.65$ \\
\hline Control & $40.94 \pm 6.65$ & $68.08 \pm 4.00$ & $86.81 \pm 8.18$ & $91.21 \pm 9.11$ & $124.07 \pm 16.42$ \\
\hline
\end{tabular}


Table 5. Oncorhynchus mykiss. Energy conversion efticiency (\%, mean \pm SD of 1.5 fish)

\begin{tabular}{|c|c|c|c|c|c|}
\hline \multirow[t]{2}{*}{ Treatment } & \multicolumn{5}{|c|}{ Weeks post-infection: } \\
\hline & 4 & 6 & 8 & 12 & 14 \\
\hline Infected & $37.94 \pm 2.19$ & $26.831 \pm 1.83^{d}$ & $26.80 \pm 1.30^{a}$ & $23.94 \pm 4.70$ & $29.23 \pm 2.66$ \\
\hline Pair-fed & $3685 \pm 0.81$ & $35.93 \pm 1.44$ & $3775 \pm 3.90$ & $27.70 \pm 1.61$ & $33.61 \pm 1.80$ \\
\hline Vaccinated & $32.33+2.82^{b}$ & $38.55 \pm 1.99$ & $38.55 \pm 1.99$ & $28.66 \pm 1.22$ & $23.30 \pm 10.23$ \\
\hline Control & $33.10 \pm 1.27$ & $34.75 \pm 0.81$ & $36.35 \pm 2.13$ & $29.14 \pm 1.11$ & $32.77 \pm 1.17$ \\
\hline
\end{tabular}

energy gain was observed in Group IV (control) at 6 and 8 wh post-infection $\left(F_{(3, \text { a) }}=4.07, \mathrm{p}<0.05\right)$. Energy increase of Group I (infected) fish was significantly lower than that in all other groups at 6 wk postinfection (right after peak parasitemia; Fig. 1) but had recovered by 8 wk post-infection (Table 4). Tukey's test indicated energy gain of this group was significantly different only from Group IV at this time (critical value $=4.53$ ). Variation in energy gain among replicates was similar to that observed for live weight gain at 12 wk post-infection

Significant differences in gross conversion efficiency were indicated at 4,6 and $8 \mathrm{wk}$ post-infection (Table 5) using Tukey's studentized range test (critical value = 4.53). Conversion efficiency of Group III (vaccinated) fish was significantly lower than Group I (infected) fish at $4 \mathrm{wk}$ post-infection but there were no other significant differences among treatments in this interval. Conversion efficiency of the Group I fish dropped dramatically at $6 \mathrm{wk}$ post-infection and was significantly lower than in all other groups for the next 2 wk (Table 5). Through the final $2 \mathrm{wk}$, (chronic phase of the disease with low parasitemias; Fig. 1), conversion efficiency of Group I recovered sufficiently such that it was no longer significantly different from that in the other treatment groups.

\section{DISCUSSION}

In the present study, food consumption decreased significantly in infected fish during the acute phase of the disease. This result was similar to earlier studies in which anorexia was related to parasitemia (Thomas \& Woo 1990, Li \& Woo 1991). As parasitemia decreased, food consumption increased and became similar to that of the control group.

There were only small differences in live weight gain between treatments, and this probably was because of the general edema and accumulation of ascitic fluid associated with cryptobiosis (Woo 1979). The more pronounced difference observed in dry weight gain through Weeks 6 and 8 post-infection could be the result of the anorexia in the infected fish However, the pair-fod fish, although fed the same amount as the infected group, showed significantly higher dry weight gain at $6 \mathrm{wk}$ post-infection. In an earlier study, Laidley et al. (1988) showed that fish infected with Cryptobia salmositica had depressed plasma T3 and T4 levels. Since thyroid hormone is essential for normal growth (Donaldson et al. 1979, Riley et al. 1993) depressed levels of this hormone may partially account for decreased weight gain. With a decrease in parasitemia $8 \mathrm{wk}$ post-infection, weight gain of infected fish was similar to all other groups for the remainder of the study. Dry weight gain of vaccinated fish did not differ significantly from control fish at any time through the 14 wk study, indicating that although these fish had low parasitemia, the infection was not severe enough to interfere with metabolism and growth.

Predictably, results for energy gain were similar to those for dry weight gain. The differences observed through Weeks 6 and 8 post-infection were also consistent with results for food consumption at the time.

One of the most meaningful indicators of the state of health of an organism is the amount of growth relative to the amount of food consumed, or gross conversion efficiency (Brett \& Groves 1979). The significant decline in conversion efficiency in infected fish from Weeks 6 to 12 post-infection gives some indication of the bioenergetic cost of cryptobiosis to the fish. This decline is even more evident when compared with results from the pair-fed fish which consumed an equivalent amount of food to the infected group. The conversion efficiency for the pair-fed group was even slightly higher than the control group. This result is consistent with earlier observations on species of fish that energy provided in limited quantities is more efficiently utilized for growth (Brett \& Groves 1979). The conversion efficiency of the vaccinated fish was similar to both the pair-fed and control fish, a good indication that the bioenergetic cost to the fish of the vaccine is negligible. 
A bioenergetic model gives an estimate of fish growth which is generally the difference between energy ingested and energy required for metabolism and growth (Weatherley \& Gill 1987). Energy ingested by both infected and pair-fed fish was reduced as a result of anorexia in the infected group. This reduction has both negative and positive effects. Anorexia inhibits protein metabolism and causes a decrease in plasma protein levels (Li \& Woo 1991). Thomas \& Woo (1990) made a similar observation when feeding a low protein diet to infected fish. The rate of multiplication of Cryptobia salmositica is directly related to plasma protein level (Li \& Woo 1991), thus a decrease in protein intake would reduce the multiplication of the pathogen. In this way, anorexia helps combat the infection

Kumaraguru et al. (1995) found that basal metabolism in infected fish was not significantly different than that of non-infected fish. However, maximum aerobic scope for activity (Fry 1971) was drastically reduced, probably as a result of destruction of red blood cells and thus reduced oxygen-carrying capacity (Kumaraguru et al. 1995). Stress causes an increase in certain metabolic processes such as depletion of liver glycogen, changes in glucose and plasma protein levels and difficulty with osmoregulation (Schreck 1981), all of which are symptomatic of Cryptobia salmositica infection (Woo 1987, 1994, Laidley et al. 1988). The overall result is less available energy for the deposition of tissue and a reduction in growth rate.

Fish that recover from the infection are protected through humoral and cellular immunity (Jones \& Woo 1987. Thomas \& Woo 1990) but at considerable bioenergetic cost to the fish and often with high mortality (Woo 1994). The present study confirmed an earlier study (Sitja-Bobadilla \& Woo 1994) in that juvenile trout produced antibodies against the live attenuated parasite and that the vaccinated fish were protected from disease. Vaccination appears to have little bioenergetic cost and serves as an effective control for this pathogen.

Acknowledgements. This study was supported by grants from the Natural Sciences and Engineering Research Council (Canada) to F.W.H.B. and P.T.K.W. and from the Department of Fisheries and Oceans (Canada) to P.T.K.W. We thank S. Li and A. Marsland for their technical assistance.

\section{LITERATURE CITED}

Archer RK (1965) Haematological techniques for use on animals. Blackwell Scientific Publications, Oxford

Beamish FWH, Nimi AJ, Lett PFKP (1975) Bioenergetics of teleost fishes: environmental influences. In: Bolis L, Maddrell HP, Schmidt-Nielsen K (eds) Comparative physiology - functional aspects of structural materials. Vorth Holland, Amsterdam, p 187-209
Beamish FWH, Trippel EA (1990) Heat increment: a static or dynamic dimension in bioenergetic models? Trans Am Fish Soc 119:649-661

Brett JR (1979) Environmental factors and growth. In: Hoar WS, Randall DJ, Brett JR (eds) Fish physiology, Vol 8 . Academic Press, New York, p 599-675

Brett JR, Groves TDD (1979) Physiological energetics. In. Hoar WS, Randall DJ, Brett. JR (eds) Fish physiology, Vol 8. Academic Press, New York, p 280-352

Donaldson EM, Fagerlund UHM, Higgs DA, McBride JR (1.979) Hormonal enhancement of growth. In: Hoar WS, Randall DJ, Brett JR (eds) Fish physiology, Vol 8. Academic Press, New York, p 456-598

Fry FE (1971) The effect of environmental factors on the physiology of fish. In: Hoar WS, Randall DJ (eds) Fish physiology, Vol 6. Academic Press, New York, p 1-98

Jones SRM, Woo PTK (1987) The immune response of rainbow trout Salmo gairdneri Richardson to the haemoflagellate Cryptobia salmositica Katz. 1951. J Fish Dis 10 395-402

Kitchell JF, Stewart DJ, Weininger D (1977) Applications of a bioenergetics model to yellow perch (Perca flavescens) and walleye (Stizostedion vitreum vitreum). J Fish Res Bd Can 34:1922-1935

Kumaraguru AK, Beamish FWH, Woo PTK (1995) Impact of a pathogenic haemoflagellate, Cryptobia salmositica Katz, on the metabolism and swimming performance of rainbow trout, Oncorhynchus mykiss (Walbaum). J Fish Dis 18: 297-305

Laldley CW, Woo PTK, Leatherland JF (1988) The stressresponse of rainbow trout to experimental infection with the blood parasite Cryptobia salmositica Katz, 1951. J Fish Biol 32:253-261

LI S, Woo PTK (1991) Anorexia reduces the severity of cryptobiosis in Oncorhynchus mykiss. J Parasitol 77:467-471

Li S, Woo PTK (1995) Efficacy of a live Cryptobia salmositica vaccine, and the mechanism of protection in vaccinated Oncorhynchus mykiss (Walbaum) against cryptobiosis. Vet lmmunol Immunopathol 48:343-353

NRC (National Research Council) (1993) Nutrient requirements of fish. National Academy Press, Washington, DC

Parr Instrument Company (1960) Oxygen bomb calorimetry and combustion methods. Technical Manual No. 130. Parr Instrument Company, Moline, IL

Ricker WE (ed) (1971) Methods for assessment of fish production in fresh waters, 2nd edn. IBP Handbook No. 3. Blackwell Scientific Publications, Oxford

Riley WW Jr, Higgs DA, Dosanjh BS, Eales JG (1993) Influence of dietary amino acid composition on thyroid function of juvenile rainbow trout, Oncorhynchus mykiss. Aquaculture 112:253-269

Schreck CB (1981) Stress and compensation in teleostean fishes: response to social and physical factors. In: Pickering $A D$ (ed) Stress and fish. Academic Press, London, p 295-322

Sitja-Bobadilla A, Woo PTK (1994) An enzymelinked immunosorbent assay (ELISA) for the detection of antibodies against the pathogenic haemoflagellate, Cryptobia salmositica Katz, and protection against cryptobiosis in juvenile rainbow trout Oncorhynchus mykiss (Walbaum), inoculated with a live vaccine. J Fish Dis 17 : $399-408$

Steel RGD, Torrie JH (1980) Principles and procedures of statistics - a biometrical approach, 2nd edn. McGraw-Hill Book Company, New York

Thomas PT, Woo PTK (1990) Dietary modulation of humoral immune response and anaemia in rainbow trout, 
Oncorhynchus mykiss (Walbaum), infected with Cryptobia salmositica Katz, 1951. J Fish Dis 13:435-446

Weatherley AH, Gill HS (1987) The biology of fish growth Academic Press, London

Wehnert SD, Woo PTK (1981) The immune responses of Salmo gairdneri during Trypanoplasma salmositica infection. Bull Can Soc Zool 11:100

Woo PTK (1971) Evaluation of the haematocrit centrifuge technique and other techniques for the field diagnosis of human trypanosomiasis and filariasis. Acta Tropica 28: 298-303

Woo PTK (1978) The division process of Cryptobia salmositica in experimentally infected rainbow trout (Salmo gairdneri). Can J Zool 56:1514-1518

Woo PTK (1979) Trypanoplasma salmositica: experimental

Responsible Subject Editor: W. Körting, Hannover, Germany infections in rainbow trout Salmo gairdneri. Exp Parasitol $47: 36-48$

Woo PTK (1987) Cryptobia and cryptobiosis in fishes. In Baker JR, Muller R (eds) Advances in parasitology, Vol 26 Academic Press, London, p 199-237

Woo PTK (1994) Flagellate parasites of fishes. In: Kreier JP (ed) Parasitic protozoa, Vol 8. Academic Press, New York, p $1-80$

Woo PTK, Li S (1990) In vitro attenuation of Cryptobia salmositica and its use as a live vaccine against cryptobiosis in Oncorhynchus mykiss. J Parasitol 76:752-755

Woo PTK, Wehnert S (1983) Direct transmission of a haemoflagellate, Cryptobia salmositica Katz, 1951 (Kinetoplastida: Bodonina) between rainbow trout under laboratory conditions. J Protozool 39:334-337

Manuscript first received: June 13, 1995

Revised version accepted: October 20,1995 